\title{
FTIR SPECTROSCOPIC TRENDS AND DNA DAMAGE IN RABBIT LENS DUE TO LONG RUN OF TAMOXIFEN TREATMENT
}

\author{
MERVAT A. A. ${ }^{1 *}$, EMAN S. M. ${ }^{2}$, EMAN M. A. ${ }^{3}$ \\ 1,2,3Biophysics and Laser Science Unit, Visual Science Department, Research Institute of Ophthalmology-Giza, Egypt \\ Email: mervat_galal18@yahoo.com
}

Received: 14 May 2019, Revised and Accepted: 04 Jul 2019

\begin{abstract}
Objective: The aim of the present work is to evaluate the molecular structure changes of the lens of rabbits and DNA damage of epithelial cells due to tamoxifen administration.

Methods: Twenty four healthy New Zealand white rabbits were divided into 2 main groups. The first group is served as control (n=12) kept untreated, second one is Tamoxifen administrative group (n=12) received orally daily dose of $15 \mathrm{mg} / \mathrm{kg}$. Rabbits were decapitated after $2,4,6$ and 8 mo, respectively. Using fourior transform infrared (FTIR) to study the molecular structure changes due to tamoxifen and comet assay analysis for discovering DNA damage.

Results: FTIR data indicated that tamoxifen affects structural components in NHOH and fingerprint region. Increases of $\beta$-turns of the protein secondary structure while, reducing the content of both $\alpha$-helix after 8 mo and Turns appeared for all periods of administrative tamoxifen were observed. On the other hand tamoxifen induced a statistically significant increase in comet assay parameters as tail moment compared to control animals that indicated DNA damage due to single or double strand break.
\end{abstract}

Conclusion: Tamoxifen uses for more than 6 mo may lead to changes in the molecular structure of the lens and damage of DNA cells. An ophthalmic baseline examination prior to anti-cancer treatment may help detect any pre-existing ocular condition and lead to reduction of ocular side effects when predisposed patients are screened and examined regularly during and after chemotherapeutic therapy.

Keywords: Chemotherapy, Tamoxifen, Lens, Cataract, FTIR, Comet assay

(C) 2019 The Authors. Published by Innovare Academic Sciences Pvt Ltd. This is an open access article under the CC BY license (http://creativecommons.org/licenses/by/4.0/) DOI: http://dx.doi.org/10.22159/ijap.2019v11i5.34109

\section{INTRODUCTION}

Cancer chemotherapy has the potential to produce acute and chronic damage in any organ system. However, some organs are more sensitive than others. Ocular toxicity induced by cancer chemotherapy is not uncommon, but the broad spectrum of reaction to injury displayed by the eye reflects the unique anatomical, physiological, and biochemical features of this essential organ Tamoxifen $\left(\mathrm{C}_{26} \mathrm{H}_{29} \mathrm{NO}\right)$ is an antiestrogen therapy described for treatment of hormone receptor breast cancer [1]. It remains the first line pharmacological therapy for pre/peri-menopausal women and is often prescribed in the post-menopausal setting for patients at higher risk of osteoporosis or those who experienced significant side effects from aromatase inhibitors [2]. Tamoxifen effectiveness is mainly attributed to its capacity to function as an estrogen receptor antagonist, blocking estrogen binding sites on the receptor, and inhibiting the proliferative action of the receptor-hormone complex. Although, tamoxifen can induce apoptosis in breast cancer cells via upregulation of pro-apoptotic factors, it can also promote uterine hyperplasia in some women. Thus, tamoxifen as a multi-functional drug could have different effects on cells based on the utilization of effective concentrations or availability of specific co-factors [3] Tajik et al., [4] proposed that tamoxifen enhances learning and memory of ovariectomized rats. The possible mechanism may be due to the protective effects against brain tissues oxidative damage.

Despite the great important role of tamoxifen, it caused undesirable side symptoms documented in literature. Aytekin et al.,[5] reported an invasive lobular carcinoma case that presented with abnormal uterine bleeding followed by metastasize in the uterus while treating with tamoxifen and recommended routine gynecological examination during treatment.

Doshi et al., [6] found toxicity to retinal Müller cells due to low daily and cumulative doses of tamoxifen. Cho et al., [7] investigated the mechanism of tamoxifen retinotoxicity using human retinal pigment epithelial (RPE)-derived (ARPE-19) and photoreceptor-derived (661W) cells and found that lysosomal membrane permeabilization as well as caspase-dependent apoptosis contributed to tamoxifeninduced cell death. Eisner and Luoh [8] stated that the risk of posterior subcapsular cataract is increased and the optic nerve head was affected due to tamoxifen. Chung et al., [9] stated that patients with low cumulative doses of tamoxifen suffered visual symptom-related foveal cystoid space and/or macular thinning. In a prospective study of breast cancer patients treated with tamoxifen, annual cataract rates were found to be $6.8 \%$ and may also cause macular crystals, macular drusen accompany yellowish spots in the macula area [10]

The aim of the present work is to evaluate the molecular structure changes of the lens of rabbits and DNA damage of epithelial cells due to tamoxifen administration for 2, 4, 6 and 8 mo.

\section{MATERIALS AND METHODS}

\section{Chemicals}

Tamoxifen was obtained from the pharmacy (Nolvadex AstraZeneca-Egypt). All other chemicals used in the experiments were obtained from Sigma Company (St. Louis, MO, USA) with the highest purity grad available.

\section{Animals}

The animal was handled according to the ARVO (The Association for Research in Vision and Ophthalmology) statements and regulations for the use of animals in research. Twenty four healthy New Zealand white rabbits of either sex, weighing 2-2.5 $\mathrm{Kg}$ were randomly selected from animal house facility at the Research Institute of Ophthalmology RIO, Giza, Egypt and the approval number is RIOETH-218. The animals were stored separately under good ventilation and adequate standard diet. They were housed in specially designed cages and maintained under constant air flow and illumination during the experimental periods (temperature: $22 \pm 2$ ${ }^{\circ} \mathrm{C}$; humidity: 45-55\%; light intensity: 300-400 lx), also away from any acoustic stress or electromagnetic radiation. The rabbits were divided in 2 main groups. The first group is served as control $(\mathrm{n}=12)$ kept untreated, second one is Tamoxifen administration group 
$(\mathrm{n}=12)$ received orally daily dose of $15 \mathrm{mg} / \mathrm{kg}$. Rabbits were decapitated after 2, 4, 6 and 8 mo, respectively.

\section{Tamoxifen administration}

Tamoxifen (Nolvadex, AstraZeneca-Egypt) was administrated orally through the stomach tube once daily with doses $15 \mathrm{mg} / \mathrm{kg}$ tamoxifen/day by gastric intubation in $0.5 \%$ hydroxypropyl methylcellulose at $5 \mathrm{ml} / \mathrm{kg}$ dose volume between 09 and $10 \mathrm{a} . \mathrm{m}$. The overall study goes on for 8 mo [11].

\section{Samples preparation}

The rabbits were sacrificed by decapitation, where the eyes were enucleated, and then opened by corneal section through the oraserrata. After removing the corneas, the iris was pulled out by forceps where the eye lens and the vitreous humour (jelly structure) were jointly removed. The lens was weighted and kept in a previously sterilized glass vials. The glass vials were flushed by dry $\mathrm{N}_{2}$ gas and stored at $-20^{\circ} \mathrm{C}$ for further analysis.

\section{FTIR spectroscopy measurements}

Previously weighted lens was freez-dried separately and mixed with $\mathrm{KBr}$ powder ( $2 \mathrm{mg}$ lens: $98 \mathrm{mg} \mathrm{KBr}$ ) then pressed to prepare the transparent $\mathrm{KBr}$ disks that will be used for the Fourier transformation infrared (FTIR) investigations. FTIR measurements were performed using Nicolet-iS5 infrared spectrometer (ThermoFisher Scientific Inc, Madison, USA) with effective resolution of $2 \mathrm{~cm}^{-1}$. Each spectrum was taken from 100 sample interferogram. The spectrometer was operated under a continuous dry $\mathrm{N}_{2}$ gas purge to remove interference from atmospheric $\mathrm{CO}_{2}$ and $\mathrm{H}_{2} \mathrm{O}$ vapor. The spectrum was baseline corrected, then smoothed with Savitsky-Golay filter to remove the noise before Fourier transformation. Three spectra from each sample were obtained and averaged using OriginPro9 software (Origin Lab Corporation, Northampton, MA, USA) to obtain the final average group spectrum.

\section{Comet assay}

The lens epithelial cells of the control and experimental groups were homogenized in a chilled homogenizer buffer, $\mathrm{pH} 7.5$, containing 75 mmol NaCl and 24 mmol Na2 EDTA (ethylenediaminetetraacetic acid) to achieve a $10 \%$ tissue solution. A potter-type homogeniser was used and samples were kept on ice during and after homogenisation. $6 \mu \mathrm{L}$ of lens homogenate were suspended on a $0.5 \%$ low-melting agarose and sandwiched between a bottom layer of $0.6 \%$ normal-melting agarose and a top layer of $0.5 \%$ low-melting agarose on fully-frosted slides. The slides were kept on ice during the polymerisation of each gel layer. After the solidification of the $0.6 \%$ agarose layer, the slides were immersed in a lysis solution (1\% sodium sarcosinate, $2.5 \mathrm{M} \mathrm{NaCl}, 100$ mmol Na2 EDTA, 10 mmol Tris-HCl, $1 \%$ triton X-100, and 10\% DMSO) at $4{ }^{\circ} \mathrm{C}$. After 1 hour, the slides were placed in an electrophoresis buffer $(0.3 \mathrm{M} \mathrm{NaOH}, 1 \mathrm{mmol} \mathrm{Na} 2 \mathrm{EDTA}, \mathrm{pH} 13)$ for $10 \mathrm{~min}$ at $0{ }^{\circ} \mathrm{C}$ to allow the DNA to unwind. Electrophoresis was performed for $10 \mathrm{~min}$ at $300 \mathrm{~mA}$ and $1 \mathrm{~V} / \mathrm{cm}$. The slides were neutralised with a Tris-HCl buffer, pH 7.5, and stained with $20 \mu \mathrm{g} / \mathrm{ml}$ ethidium-bromide for 10 min. Each slide was analysed using a fluorescence microscope (with excitation filter of 420-490 nm [issue $510 \mathrm{~nm}$ ]). One-hundred cells were analyzed on each slide. We used the Komet 5 image analysis software is developed by Kinetic Imaging, Ltd. (Liverpool, UK) linked to a charge-coupled device (CCD) camera to assess the quantitative and qualitative extent of DNA damage in the cells. Tail length $(\mu \mathrm{m})$ is the distance of DNA migration from the centre of the body of the nuclear core and is used to evaluate the extent of DNA damage. The tail moment is defined as the product of the tail length and the fraction of total DNA in the tail (tail moment = tail length $\mathrm{x} \%$ of DNA in the tail). Both the tail length and tail moment were measured automatically using image analysis software [12].

\section{Statistical analysis}

The results are expressed as the mean $\pm \mathrm{SD}$. Groups and statistically compared using one way-ANOVA. The significance level was set at $\mathrm{p}<0.05$. Spectral analysis was performed using Origin Pro software 2015 (Origin Lab Corporation, Northampton, MA, USA).

\section{RESULTS}

Fig. 1 illustrated the absorption spectra of FTIR and the deconvolution spectra for control lens tissue of rabbits and treated with tamoxifen (15 mg/kg tamoxifen/day) for 2,4,6 and $8 \mathrm{mo}$, respectively. After deconvolution, the control spectra degraded to eleven peaks and can be displayed into three regions $4000-3000 \mathrm{~cm}-1$ that related to NH$\mathrm{OH}, 3000-2800 \mathrm{~cm}-1$ that related to $\mathrm{CH}$ and $2000-1000 \mathrm{~cm}-1$ that represent the fingerprint region. The assignments of all bands that were eleven in control are expressed in tables 1, 2 and 3 as follow: (1)strOH at $3656 \pm 4,3580 \pm 8$,(2) OHasym at $3458 \pm 6$, (4) strOHsym at $3278 \pm 3$, (5) strNHsym at $3174 \pm 3$, (6)asymCH3 at $2975 \pm 7$, (8) symCH3 at $2872 \pm 5$, (10) Ester $\mathrm{C}=0$ at $1641 \pm 2$, (11) amide II at $1539 \pm 4,(12)$ COOsym at $1406 \pm 4$ and (14) asymPO2. Giving the bands numbers to facility their assignment and the missing numbers of peaks are new vibrations appeared in tamoxifen treated groups. The assignments were as previously mentioned by Eman 2015 [13]

The numbers of bands were decreased due to tamoxifen administration to 9 bands after 2, 8months and to 7 bands after 4,6 mo. Table 1 indicated the bands position and their width in $\mathrm{NH}-\mathrm{OH}$ region to all tamoxifen administration groups compared to control. There is a higher frequency of $\mathrm{str}_{\mathrm{OH}} \mathrm{O}$ appeared after 2 mo of tamoxifen. Also there is a statistically significant decrease $(p<0.05)$ in the lower frequency that appeared after 4, 6 and 8 mo of tamoxifen groups and statistically significant increase $(\mathrm{p}<0.05)$ in their width. Disappear of mode of vibration related to (2) $\mathrm{OH}_{\text {asym }}$ after 4 and $6 \mathrm{mo}$ and significant increase in its width after 2 and 8 mo. Appeared of a vibration mode related to (3) ${ }_{\text {str }} \mathrm{NH}_{\text {asym }}$ after 4 and 6 mo of treatments with tamoxifen. Disappearance of $(4){ }_{\text {str }} \mathrm{OH}_{\text {sym }}$ vibration mode after 2,4 and 6 mo of tamoxifen was observed. A significant increase $(p<0.05)$ in band position and band width of $(5)$ str $\mathrm{NH}_{\text {sym }}$ after 2 mo of tamoxifen and disappeared of this mode of vibration for all other treated groups.

Table (2) represented the $\mathrm{CH}$ region of all tamoxifen groups compared to control. Disappeared of asym $\mathrm{CH}_{3}$ vibration mode after 2,4 and 6 mo of administration of tamoxifen and appeared a new vibration mode related to (7) asym $\mathrm{CH}_{2}$ after 2 and 4 mo of tamoxifen. Detected of (9) ${ }_{\text {sym }} \mathrm{CH}_{2}$ vibration mode after 6 mo of treated with tamoxifen.

Table (3) indicated fingerprint function groups to all groups' administration with tamoxifen in comparison with the control group. A significant change in band position due to $(10) \mathrm{C}=0$ vibration in all tamoxifen groups and significant increase $(\mathrm{p}<0.05)$ in band width was observed after 8 mo. Amide II vibration position wasn't affected but the band width was significant decrease $(p<0.05)$ after 2,4 and 6 mo and significant increase $(\mathrm{p}<0.05)$ after 8 mo of tamoxifen administration. Significant changes in both vibration modes $\mathrm{COO}_{\mathrm{sym}}$ and ${ }_{\text {asym }} \mathrm{PO}_{2}$ and their width was observed due to tamoxifen treatment. Detected of new two modes of vibration related to (12) $\mathrm{CH}_{3 \text { Deform }}(14)$ COC after 2, 8 mo of tamoxifen treatment.

Table 1: Peaks assignment of NHOH Region $4000-3000 \mathrm{~cm}^{-1}$

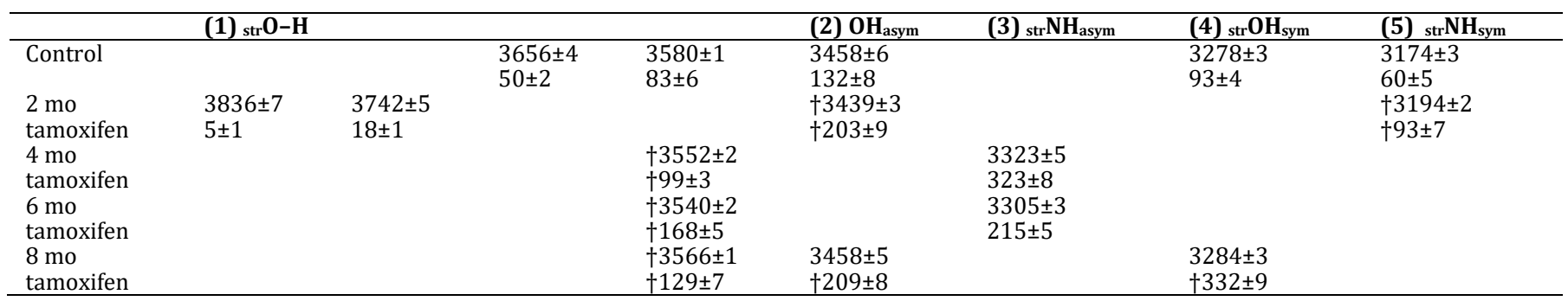

† Statistical significant $\mathrm{p}<0.05$, first line is the wavenumber and the second is the width, $(\mathrm{n}=5$ and the data given in mean \pm SD) 

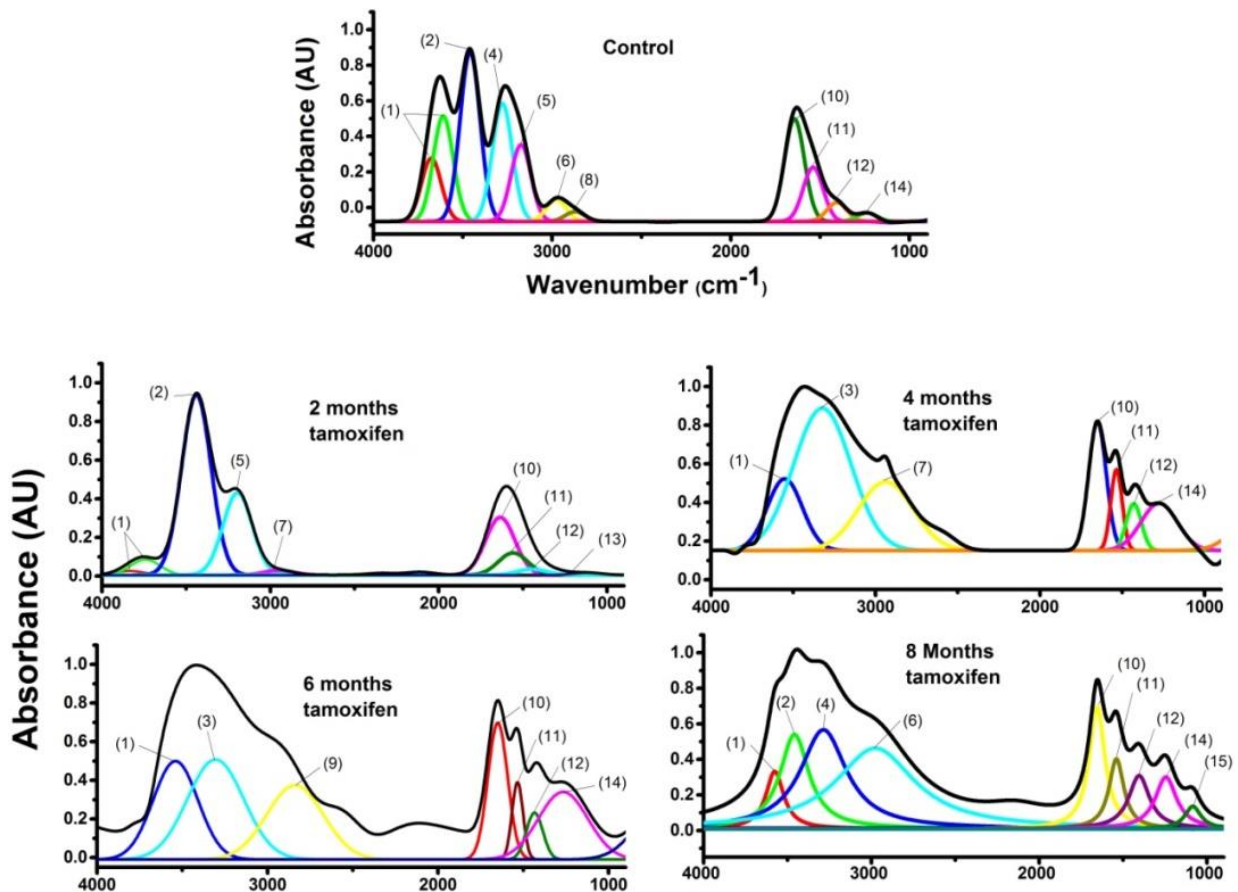

Wavenumber $\left(\mathrm{cm}^{-1}\right.$,

Fig. 1: FTIR spectra for lens of control rabbits and all groups treated with tamoxifen

Table 2: Assignment of peaks in $\mathrm{CH}$ region $3000-2800 \mathrm{~cm}^{-1}(\mathrm{n}=5$, mean $\pm \mathrm{SD})$

\begin{tabular}{lllll}
\hline & $(\mathbf{6})_{\text {asym }} \mathbf{C H}_{3}$ & $\mathbf{( 7 )}$ asym $\mathbf{C H}$ & $\mathbf{( 8 )}_{\text {sym }} \mathbf{C H}$ & \\
\hline control & $2975 \pm 717 \pm 1$ & $2948 \pm 95 \pm 1$ & $2872 \pm 58 \pm 2$ & \\
2 mo Tamoxifen & & $2938 \pm 6149 \pm 6$ & & \\
4 mo Stamoxifen & & & & $2838 \pm 4160 \pm 6$ \\
6 mo Tamoxifen & & & \\
8 mo Tamoxifen & $2976 \pm 517 \pm 2$ & & \\
\hline
\end{tabular}

† Statistical significant $p<0.05$, First line is the wavenumber and the second is the width, $(n=5$ and the data given in mean $\pm S D$ )

Table 3: Fingerprint region peaks in the range $1700-1000 \mathrm{~cm}^{-1}(\mathrm{n}=5$, mean $\pm S D)$

\begin{tabular}{|c|c|c|c|c|c|c|}
\hline & (10)Ester $\mathrm{C}=0$ & (11)Amide II & $(12) \mathrm{COO}_{\text {sym }}$ & (13) $\mathrm{CH}_{\text {3Deform }}$ & $(14)_{\text {asym }} \mathrm{PO}_{2}$ & (15)COC \\
\hline control & $1641 \pm 280 \pm 8$ & $1539 \pm 443 \pm 5$ & $1406 \pm 415 \pm 3$ & & $1236 \pm 27 \pm 1$ & \\
\hline 2 mo Tamoxifen & $\dagger 1628 \pm 165 \pm 6$ & $1548 \pm 5+25 \pm 2$ & $\dagger 1444 \pm 37 \pm 1$ & $1322 \pm 45 \pm 1$ & & \\
\hline 4 moTamoxifen & $\dagger 1650 \pm 189 \pm 10$ & $1535 \pm 236 \pm 6$ & $\dagger 1430 \pm 2 \dagger 30 \pm 2$ & & $\dagger 1276 \pm 5+68 \pm 3$ & \\
\hline 6 mo Tamoxifen & $\dagger 1650 \pm 1103 \pm 7$ & $1534 \pm 333 \pm 5$ & $\dagger 1434 \pm 2 \dagger 30 \pm 2$ & & $\dagger 1266 \pm 4 \dagger 127 \pm 3$ & \\
\hline 8 mo Thstamoxifen & $\dagger 1655 \pm 1 \dagger 114 \pm 5$ & $1539 \pm 2 \dagger 107 \pm 2$ & $\dagger 1429 \pm 2 \dagger 150 \pm 7$ & & $\dagger 1248 \pm 2 \dagger 155 \pm 4$ & $1084 \pm 3117 \pm 5$ \\
\hline
\end{tabular}

$\dagger$ Statistical significant $\mathrm{p}<0.05$, first line is the wavenumber and the second is the width, $(\mathrm{n}=5$ and the data given in mean \pm SD)

Fig. 2 studied the secondary structure of proteins according to amide I vibration mode to control and all tamoxifen administration groups. By using the curve enhancement procedure, five structural bands were found due to $\beta$-turn, $\alpha$ helix and $\beta$-sheet. After tamoxifen treatment the number of structural component were decreased to 4 after 2 and 4 mo then increased to 6 and 5 after 6 and $8 \mathrm{mo}$ respectively. To determine the concentration of each structural component, the area percentage of each one was given in table (4). A new component was detected after all periods of tamoxifen treatment related to Turns with percentage area $14.7 \pm 1.4,12.2 \pm 1.6$, $6.5 \pm 0.8$ and $2.1 \pm 1.0$ after $2,4,6$ and 8 mo, respectively. Content of $\beta$ turn was significant decrease $(\mathrm{p}<0.05)$ after 2,4 and 6 mo of tamoxifen treatment but significant increased $(\mathrm{p}<0.05)$ after 8 mo of treatment. Also a significant decrease $(\mathrm{p}<0.05)$ in $\alpha$-helix content associated with a significant increase $(\mathrm{p}<0.05)$ of $\beta$-sheet content due to 8 mo of tamoxifen treatment.

Table 4: Area percentage differences for bands in Amide I for all groups ( $n=5$, mean \pm SD)

\begin{tabular}{|c|c|c|c|c|}
\hline & $\beta$-turn & $\alpha$-helix & Turns & $\beta$-sheet \\
\hline Control & $23.6 \pm 2.8$ & $49.3 \pm 1.8$ & & $27.1 \pm 3.4$ \\
\hline 2 mo tamoxifen & $\dagger 5.8 \pm 2$ & $48.8 \pm 3.0$ & $14.7 \pm 1.4$ & $30.7 \pm 4.1$ \\
\hline 4 mo tamoxifen & $\dagger 5.7 \pm 2.3$ & $48.6 \pm 4.6$ & $12.2 \pm 1.6$ & $33.5 \pm 2.6$ \\
\hline 6 mo tamoxifen & $17.4 \pm 3.1$ & $46.8 \pm 2.5$ & $6.5 \pm 0.8$ & $29.3 \pm 1.4$ \\
\hline 8 mo tamoxifen & $\dagger 34.2 \pm 1.9$ & $\dagger 13.1 \pm 2.8$ & $2.1 \pm 1.0$ & $\dagger 50.6 \pm 3.8$ \\
\hline
\end{tabular}

† Statistical significant $\mathrm{p}<0.05$, $(\mathrm{n}=5$ and the data given in mean \pm SD $)$ 


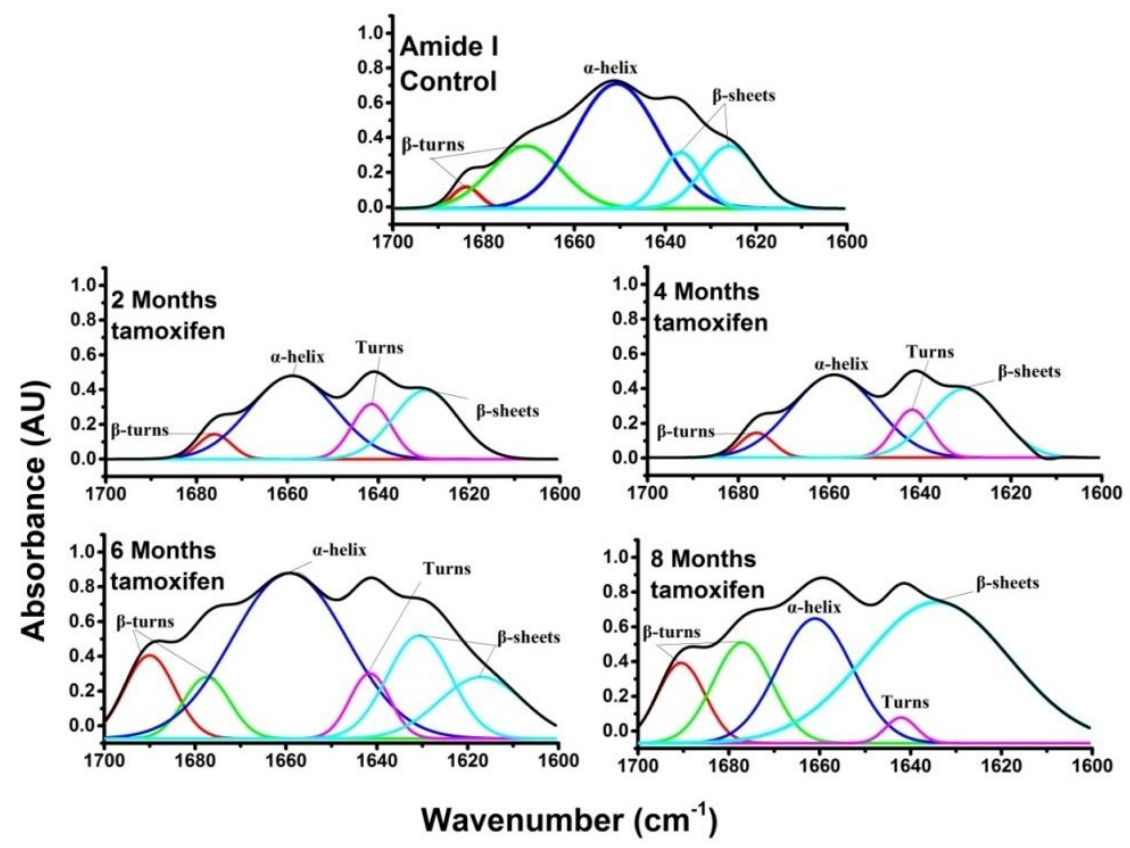

Fig. 2: Amide I region $\left(1700-1600 \mathrm{~cm}^{-1}\right)$ to control and all treated tamoxifen groups

Fig. 3 illustrated examples of comet images: A) normal that is clearly head visible nucleus and, B) damage cell showed head and a fragmented tail DNA. Calculated comet assay parameters from komet 5 software were illustrated in fig. (4). The control values of percentage tail cells, tail length, percentage tail DNA and tail moment were $5 \% \pm 1,2.03 \mu \mathrm{m} \pm 0.14,2.4 \% \pm 0.07$ and $4.87 \pm 0.13$ unit, respectively. The histogram (fig. 4) indicated a significant increase $(\mathrm{p}<0.05)$ in all parameters related to comet analysis except tail length for groups II and III that treated with tamoxifen for 2 and 4 mo.

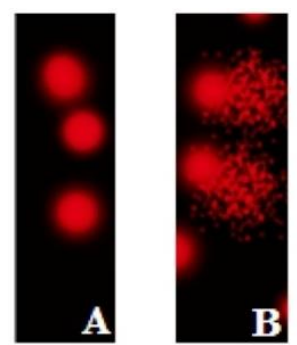

Fig. 3: Examples of comet assay images: $A$ is the normal cells and $B$ is the damaged cells extending with tail

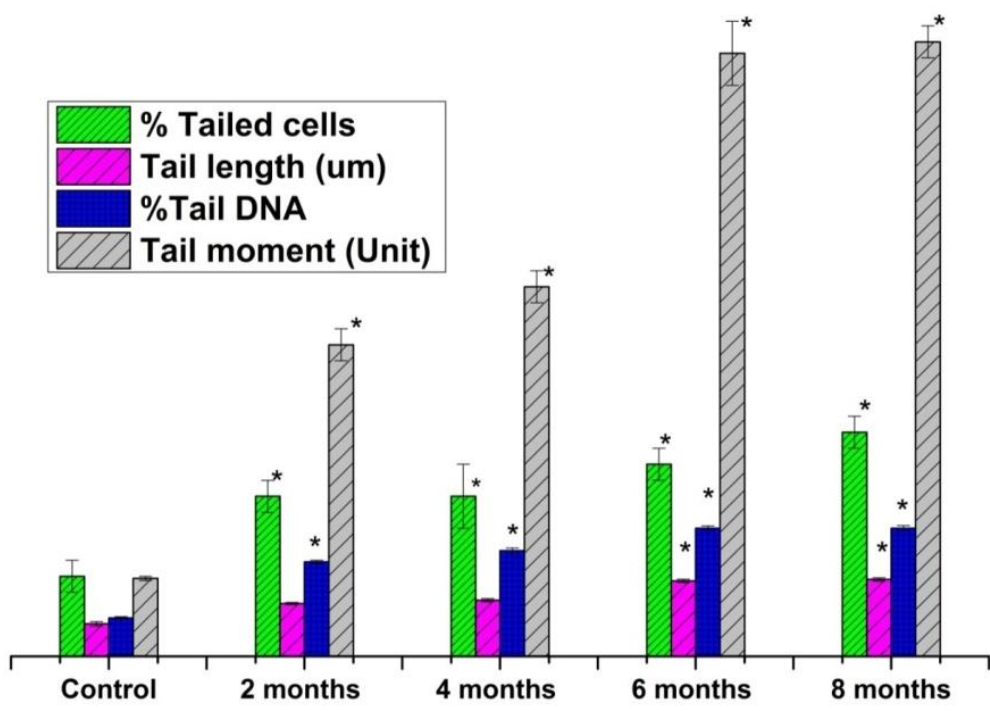

Fig. 4: Histogram of comet parameters (*statistical significant $p<0.05$ ) 


\section{DISSCUTION}

Ocular side effects results from any medication depend on combined several factors. First, cytotoxic effect because being administrative chemotherapeutic medicine. Second, toxicity results from the cumulative dose of drug. Third, the physiological response to the treatment from the patient to other would differ. Finally, the frequency with which symptoms are reported depends greatly on the expectations and communications among providers, investigators, and patients [8].

The present work elucidates the molecular structure changes in the lens of rabbits due to administrative $15 \mathrm{mg} / \mathrm{kg}$ tamoxifen for different periods. By using FTIR measurements which performed to identify the biomolecules [14], the difference between the normal lens tissue and treated one was elucidated. A higher frequency of strOH that appeared after 2 mo of tamoxifen and significant decrease $(\mathrm{p}<0.05)$ in lower frequency that appeared after 4, 6 and 8 mo indicates the formation of new type of hydrogen bonds with different structural states. The changes in vibration mode OHasym is linked to weaker hydrogen bonds. The shifting of the strNHsym band toward higher wavenumber and width increase indicate that some hydrogen bonds have been destructive due to administration of tamoxifen or weaker hydrogen bonds have been existed. Appeared in different vibration modes in the $\mathrm{CH}$ region is suggesting a loss of membrane fluidity [15]. Experimentally observed spectral changes in fingerprint region for tissues have been qualitatively reported to correlate to water content and are examples of physiological situations where spectral complexity emerges beyond the isolated molecule vibrational bands assignment. Protein-water interactions are known to play a critical role in the function of several biological systems and macromolecules including collagen in tissues. Small changes in structure and dynamical behavior of water molecules at the peptide-water interface can effectively change both the structure and dynamics of the protein function [16]. By calculating the intensity ratio between amide I and amide II for control lens tissue, it was 2.23 that high to characterize the normal lens tissue. The ratio was decreased gradually to reach 1.79 after 8 mo of administrative tamoxifen. According to the literature, this is associated with the contents of water in the nuclear lenses [17]. The various content of water in the nucleus for the normal lens in comparison with the tamoxifen treated one is observed and indicated a cataract lens that in agreement with Paluszkiewicz et al., [18] in a study illustrated IR spectra to normal lens and cataractous one.

Also, the data indicated that the turn's structure appeared in the Amide I band for all groups treated with tamoxifen (fig. 2 and table 4) but not for the normal lens. For the treated sample with tamoxifen for 8 mo the significant increase of the $\beta$-turn component in the Amide I band, is detected. According to the literature, the $\beta$ type protein secondary structure formation is coupled with a reduction of ordered $\alpha$-helix conformation and appeared of turns [17]. This may suggest that in this part of the cataractous lens the deformation upon eye disease.

Comet assay was used to detect DNA damage such as strand breaks and DNA-protein cross links. In the current study, the observed increased DNA migration in administrative groups may be attributed to the induction of DNA strand breaks. In this study, rabbits' lens epithelial cells DNA damage induced by administration was revealed by various comet assay parameters that were provided by the image analysis software including tail moment, percentage of DNA in the tail, tail length and percentage of tailed cells. These parameters showed a significant increase in administrative groups compared to the control group (which showed some degree of DNA damage). Degree of DNA damage observed in control group might be explained by the fact that about 10,000 oxidation hits to DNA per cell have been estimated to occur per day within the human body, and more than 35 different forms of oxidized bases are found in DNA. Most damage is repaired by effective DNA-repair enzymes, but some damage escapes repair, causing permanent damage. Parameters measurements show that tamoxifen administration produces more DNA damage. The higher period, the higher DNA damage occurs. Moreover, a comparative study has shown accumulation of modified DNA bases in Fischer rats treated with tamoxifen. Also the same modification in DNA was detected in DBA/2 and C57BL/6 mice [19].

An additional activity of tamoxifen may be the cause of induced cataract is the finding that tamoxifen is a potent blocker of chloride channels suggests a mechanism whereby it might elicit specific side effects when administered therapeutically. Functional chloride channels were found to be necessary for normal lens clarity, and these channels were blocked by tamoxifen. Tamoxifen induced lens opacity in organ culture at similar concentrations to those required to block lens chloride channels in isolated patches [20].

\section{CONCLUSION}

Tamoxifen was found to be the most used chemotherapy drug especially for estrogen positive breast cancer. This increases the importance of studying its side effects. Its uses for more than 6 mo may lead to changes in the molecular structure of the lens and damage of DNA cells. An ophthalmic baseline examination prior to anti-cancer treatment may help detect any pre-existing ocular condition and lead to reduction of ocular side effects when predisposed patients are screened and examined regularly during and after chemotherapeutic therapy.

\section{AUTHORS CONTRIBUTIONS}

All the author have contributed equally

\section{CONFLICT OF INTERESTS}

Declared none

\section{REFERNCES}

1. Ursulovic T, Milovanovic Z, Medic Milijic N, Gavrilovic D, Plesinac Karapandzic V, Susnjar S. The influence of PTEN protein expression on disease outcome in premenopausal hormone receptor-positive early breast cancer patients treated with adjuvant ovarian ablation: a long-term follow-up. J BUON 2018;23:902-9.

2. Jansen LE, Teft WA, Rose RV, Lizotte DJ, Kim RB. CYP2D6 genotype and endoxifen plasma concentration do not predict hot flash severity during tamoxifen therapy. Breast Cancer Res Treat 2018;171:701-8.

3. Rouhimoghadam M, Safarian S, Carroll JS, Sheibani N, Bidkhori G. Tamoxifen-induced apoptosis of MCF-7 Cells via GPR30/PI3K/MAPKs interactions: verification by ODE modeling and RNA sequencing. Front Physiol 2018;9:907.

4. Tajik A, Rezayof A, Ghasemzadeh Z, Sardari M. Activation of the dorsal hippocampal nicotinic acetylcholine receptors improves tamoxifen-induced memory retrieval impairment in adult female rats. Neuroscience 2016;327:1-9.

5. Aytekin A, Bilgetekin I, Ciltas A, Ogut B, Coskun U, Benekli M. Lobular breast cancer metastasis to uterus during adjuvant tamoxifentreatment: a case report and review of the literature. J Cancer Res Ther 2018;14:1135-7.

6. Doshi R, Fortun J, Kim B, Dubovy S, Rosenfeld B. Pseudocystic foveal cavitation in tamoxifen retinopathy. Am J Ophthalmol 2014; 157:1291-8.

7. Cho KS, Yoon YH, Choi JA, Lee SJ, Koh JY. Induction of autophagy and cell death by tamoxifen in cultured retinal pigment epithelial and photoreceptor cells. Invest Ophthalmol Vis Sci 2012;53:5344-53.

8. Eisner A, Luoh S. Breast cancer medications and vision: effects of treatments for early-stage disease. Curr Eye Res 2011;36:867-85.

9. Chung H, Kim D, Ahn S, Gone Kim J, Lee J, Lim J, et al. Early detection of tamoxifen-induced maculopathy in patients with low cumulative doses of tamoxifen. Ophthalmic Surgery, Lasers and Imaging Retina; 2010.

10. Parkkari M, Paakkala A, Salminen L, Holli K. Ocular side-effects in breast cancer patients treated with tamoxifen and toremifene: a randomized follow-up study. Acta Ophthalmol Scandina Vica 2003;81:495-9.

11. Greaves P, Goonetilleke R, Nunn G, Topham J, Orton T. Twoyear carcinogenicity study of tamoxifen in Alderley Park Wistar-derived rats. J Cancer Res 1993;53:3919-24. 
12. Eman MA, Mervat AA. Effects of bilberry on deoxyribonucleic acid damage and oxidant-antioxidant balance in the lens, Induced by Ultraviolet Radiation. Malays J Med Sci 2014;21:11-8.

13. Eman M. Ftir analysis for retina associated with diabetic changes and treatment with oat. Int J Pharm Pharm Sci 2015; 7:277-80.

14. Janakiraman M. Protective efficacy of silver nanoparticles synthesized from silymarin on cisplatin induced renal oxidative stress in albino rat. Int J Appl Pharm 2018;10:110-6.

15. Loffhagen N, Hartig C, Geyer W, Voyevoda M, Harms H. Competition between cis, trans, and cyclopropane fatty acid formation and its impact on membrane fluidity. Eng Life Sci 2007;7:67-74.

16. Sato ET, Martinho H. First-principles calculations of Raman vibrational modes in the fingerprint region for connective tissue. Biomed Opt Express 2018;9:1728-34
17. Lin SY, Li MJ, Liang RC, Lee SM. Non-destructive analysis of the conformational changes in human lens lipid and protein structures of the immature cataracts associated with glaucoma. Spectrochim Acta A Mol Biomol Spectrosc 1998;54A:1509-17.

18. Paluszkiewicz C, Piergies N, Sozanska A, Chaniecki P, Rękas M, Miszczyk J, et al. Vibrational microspectroscopy analysis of human lenses. Spectrochim Acta A Mol Biomol Spectrosc 2018;188:332-7.

19. White IN, de Matteis F, Davies A, Smith L, Crofton Sleigh C, Venitt $\mathrm{S}$, et al. Genotoxic potential of tamoxifen and analogues in female Fischer F344/n rats, DBA/2 and C57BL/6 mice and in human MCL-5 cells. Carcinogenesis 1992;13:2197-203.

20. Zhang JJ, Jacob TJ, Valverde MA, Hardy SP, Mintenig GM, Sepulveda FV, et al. Tamoxifen blocks chloride channels. A possible mechanism for cataract formation. J Clin Invest 1994; $94: 1690-7$. 